\title{
Microsized Graphite Sensors for Potentiometric Determination of Metronidazole and Spiramycin
}

\author{
F.I. Khattab, N.K. Ramadan, M.A. Hegazy, ${ }^{*}$ and N.S. Ghoniem \\ Analytical Chemistry Department, Faculty of Pharmacy, Cairo University, \\ Kasr-El-Aini 11562-Cairo-Egypt
}

Received 15 August 2010; accepted 14 March 2011

\begin{abstract}
Two microsized graphite-design sensors based on ionophore technique, polyvinyl chloride carboxylated (PVC-COOH) and $\beta$-cyclodextrin $(\beta-\mathrm{CD})$, are used for fabrication of two membrane sensors for the two studied drugs, metronidazole (MZ), sensor 1, and spiramycin (SP), sensor 2. Fast and stable Nernstian responses near $1 \times 10^{-5}$ - $1 \times 10^{-3} \mathrm{M}$ for $\mathrm{MZ}$ and $1 \times 10^{-5}-1 \times 10^{-2} \mathrm{M}$ for $\mathrm{SP}$ over $\mathrm{pH}$ range 5.5-7.5 for the two electrodes reveal the performance characteristics of these electrodes which have been evaluated according to IUPAC recommendations. The aim of this work is to develop a new, simple, accurate and precise method for the determination of MZ and SP in their binary mixtures, which can be applied in routine quality control. The method is successively applied for the determination of the two drugs in their pharmaceutical formulations. Validation of the method according to the quality assurance standards shows suitability of the proposed electrodes for the use in the quality control assessment of these drugs. The recovery percentages for the determination of the two drugs by the two proposed selective electrodes are $99.86 \pm 0.249 \%$ and $99.69 \pm 0.856 \%$ for sensors 1 and 2, respectively. Statistical comparison between the results obtained by this method and the reported one is done and no significant difference is found.
\end{abstract}

Keywords: metronidazole (MZ), spiramycin (SP), poly(vinyl chloride) carboxylated PVC-COOH, $\beta$-cyclodextrin ( $\beta$-CD), pharmaceutical formulations.

\section{Introduction}

Metronidazole (MZ) is the reference agent of the nitroimidazole anti-infective family. It is chemically designated as 2-(2-methyl-5-nitro-1H-imidazol-1-yl) ethanol [1]. It is used mainly in the treatment of anaerobic bacteria and protozoa as it is reduced to its active form intracellularly. Besides, it has a radio-

\footnotetext{
* Corresponding author. E-mail address: mahahgazy@yahoo.com
} 
sensitizing effect on hypoxic tumor cells [2]. In addition of being a human medicine, MZ has also been used as antiparasitic in the veterinary field [3].

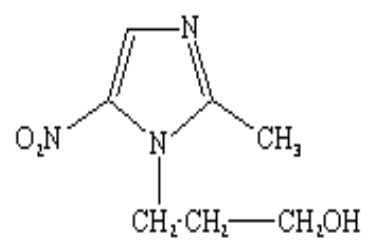

Metronidazole: mol. formula: $\underline{\mathrm{C}}_{6} \underline{\mathrm{H}}_{9} \underline{\mathrm{N}}_{3} \underline{\mathrm{O}}_{3}$; mol. weight: $171.15 \mathrm{~g} \mathrm{~mol}^{-1}$.

Spiramycin (SP) is chemically designated as $(6 R, 7 R, 9 R, 10 R, 11 E, 13 E, 16 R)-10-$ $\{[(2 R, 5 S, 6 R)-5$-(dimethylamino)-6-methyltetrahydro-2H-pyran-2-yl]oxy $\}-5,9,16$ -trimethyl-2-oxo-7-(2-oxoethyl)oxacyclohexadeca-11,13-dien-6-yl 3,6-dideoxy4- $O$-(2,6-dideoxy-3-C-methyl- $\alpha$-L-ribo-hexopyranosyl)-3-(dimethylamino)- $\alpha$-Dglucopyranoside [1]. It is isolated from the streptomyces ambofaciens and is a natural mixture of three components: SP I together with its 3-acetyl (SPII) and 3propanoyl (SPIII) [4] with minimum of $85 \%$ of SP I, and a maximum of $5 \%$ for SP II and $10 \%$ for SPR III [5]. It is well absorbed after oral administration and distributed in the tissues, especially lungs, liver and kidney [6].

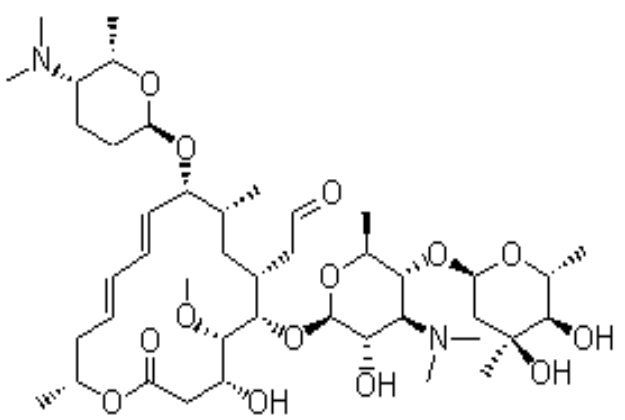

Spiramycin: mol. formula: $\mathrm{C}_{43} \mathrm{H}_{74} \mathrm{~N}_{2} \mathrm{O}_{14}$; mol. weight: $843.06 \mathrm{~g} \mathrm{~mol}^{-1}$.

Several methods have been reported for the determination of either MZ or SP each in its single pharmaceutical formulations. Several methods were reported for the determination of $\mathrm{MZ}$ in biological fluids, in pharmaceutical dosage forms, in combination with other drugs and in the presence of its metabolites, using spectrophotometry [7], thin layer chromatography (TLC) [8], liquid chromatography (LC) [9,10], high performance liquid chromatography (HPLC) [11], voltammetry [12], flow injection chemiluminescence analysis [13], nuclear magnetic resonance spectrometry (NMR) [14], capillary electrophoresis [15] and potentiometrically, using nanostructure thin film on the gold electrode through continuous pulsed-potential technique [16]. Also, different techniques have been described for the determination of SP, including titremetry [17], spectrophotometry [18], TLC [19], LC [20], HPLC [21,22], capillary electrophoresis [23], voltammetry [24], and immunological assay [25].

The combinations of $\mathrm{MZ}$ and SP have been developed on the basis of complementary of the antibacterial activity of both compounds in vitro. This binary mixture has been determined in plasma, saliva and gingival crevicular fluid by LC-MS/MS [10], and in fish muscle using HPLC with UV detection 
[26]. Determination of MZ and SP by HPLC and HPTLC in tablets has been also reported [27]. A comprehensive literature search revealed the lack of any potentiometric techniques for the determination of MZ and SP in tablets.

The scientific novelty of the present work is that the method used is simple, rapid, selective and less expensive and less time consuming compared with other published LC, TLC and HPLC methods.

The focus of the present study is to develop and validate a potentiometric method for the determination of MZ and SP in their combined tablets dosage form.

Microelectrodes have been the subject of much research in recent years [28]. The advantages they offer over conventional electrodes are well known [29]. Their small physical size allows exploration of microscopic domains, such as biological systems. Their fast response time, due to the reduced diffusion layer, allows rapid scan rates to be used [30].

Metallic and graphite-based conductors of many geometric shapes have been suggested, such as wire, disc and cylinders [31-33]. These electrodes behave as two interface devices, membrane/electrolyte interface and membrane/metal interface [34]. Thus, the membrane potential in the cell regards as the electric potential difference between the two interfaces.

Membranes have been suggested to be prepared from polymer, ionophore and plasticizer [30]. The role of the polymer is to provide an inert solid support structure in which the rest of components are embedded. The ionophore can be viewed as a molecular receptor, because its chemical structure provides well defined inclusion cavities with a specific receptor function [35]. The ionophores can accommodate a wide variety of organic, inorganic, as well as biologic guest molecules to form stable host-guest inclusion complexes or nanostructure supramolecular assemblies in their hydrophobic cavity, showing high molecular selectivity and enantioselectivity [36]. The plasticizer plasticizes the membrane and affects the lipophilicity of the polymer membrane. It also alters the distribution coefficients $(\mathrm{K})$ of different species, thus affecting the performance characteristics of the electrode [37].

The high selectivity of these electrodes imparts a great advantage over other techniques [38]. Analytes in colored, turbid and viscous samples can be determined accurately. They show rapid response to change in the concentration. Furthermore, they may be used for measurement over a wide concentration range. Ion selective electrodes are generally tolerant to small changes in $\mathrm{pH}$. A further advantage is that they are relatively simple and not expensive to develop, set up and run. Moreover, the chemical design of the electrodes has been developed to give superior selectivity and response [38].

The present work includes microsized graphite-design sensors that based on ionophore technique, $\mathrm{PVC}-\mathrm{COOH}$ and $\beta-\mathrm{CD}$ are used for fabrication of membrane sensors for the two studied drugs.

The microsized graphite rods are coated with thin films of PVC-COOH- $\beta-C D-$ dioctylphthalate (DOP), and used as potentiometric sensors for MZ and SP. Upon soaking these sensors in MZ and SP test solutions, a homogenous electroactive layer from PVC-COOH- $\beta$-CD-DOP-Drug is formed which induces a potentiometric response for the two studied drugs. 
Sensors 1 and 2 are simply fabricated without the need of ion association complex. They are only preconditioned by soaking in the corresponding drug solution where acid-base interactions take place between the dissociated $\mathrm{COO}^{-}$ group of the PVC and quaternary nitrogen atom of the drug in the test solution until chemical equilibrium is attained.

\section{Experimental}

\section{Apparatus}

- Jenway digital ion analyzer model 3330 (UK) with $\mathrm{Ag} / \mathrm{AgCl}$ double junction reference electrode no. no Z113107-1EAPW (Aldrich Chemical Co.).

- Jenway (UK) pH glass electrode no. 924005-BO3-Q11C.

- Magnetic stirrer, Bandelin Sonorox, Rx510S (Hungarian).

\section{Reference samples}

Metronidazole and spiramycin have kindly been supplied by El Pharonia Pharmaceuticals, new borg El-arab City, Alexandria, A.R.E. They are certified to contain $4412 \mathrm{IU} \mathrm{mg}{ }^{-1}$ and $99.90 \% \mathrm{w} / \mathrm{w}$, respectively, according to the manufacturer's method.

\section{Pharmaceutical formulations}

Spirazole ${ }^{\circledR}$ tablets, batch no.1288009, are labeled to contain $125 \mathrm{mg}$ of $\mathrm{MZ}$ and 750000 IU of SP, and are manufactured by El Pharonia Pharmaceuticals, New Borg El-Arab City, Alexandria, A.R.E.

\section{Reagents}

All chemicals and reagents used throughout this work were of analytical grade. Double distilled water was used.

Polyvinyl chloride carboxylated (PVC-COOH) and $\beta$-cyclodextrin $(\beta-\mathrm{CD})$ were purchased from Fluka chemie (GmbH Germany). Tetrahydrofuran (THF) was purchased from BDH (limited Poole, England), while dioctyl phthalate (DOP) was purchased from Sigma/Aldrich (St. Louis, MO). Sodium hydroxide 0.1 M aqueous solution and hydrochloric acid $0.1 \mathrm{M}$ aqueous solution were prepared and obtained from Prolabo (VWR International, West Chester, PA).

\section{Standard solutions}

- MZ standard stock solution $\left(1 \times 10^{-2} \mathrm{M}\right)$ : it was prepared by transferring $0.171 \mathrm{~g}$ of MZ into a $100 \mathrm{~mL}$ volumetric flask, and the volume was then completed to the mark with double distilled water.

- MZ working solutions $\left(1 \times 10^{-5}-1 \times 10^{-3} \mathrm{M}\right)$ : they were prepared by suitable dilution from their stock solution using double distilled water.

- SP standard stock solution $\left(1 \times 10^{-1} \mathrm{M}\right)$ : it was prepared by transferring $8.431 \mathrm{~g}$ of SP into a $100 \mathrm{~mL}$ volumetric flask, and the volume was then completed to the mark with double distilled water.

- SP working solutions $\left(1 \times 10^{-5}-1 \times 10^{-2} \mathrm{M}\right)$ : they were prepared by suitable dilution from their stock solution using double distilled water. 


\section{Procedures}

Preparation of electroactive coating membrane: $(\beta-C D / D O P / P V C-C O O H)$ In a glass Petri dish (5 cm diameter), a portion of $0.9 \mathrm{~g} \mathrm{PVC}-\mathrm{COOH}$ was thoroughly mixed with $0.35 \mathrm{~g}$ DOP and $0.3 \mathrm{~g} \beta-\mathrm{CD}$, then dissolved in $15 \mathrm{~mL}$ THF. The Petri dish was covered with a filter paper and left to stand for $1 \mathrm{~h}$ to allow slow solvent evaporation. A thick homogeneous solution was produced.

\section{Sensor 1 fabrication (MZ-coated graphite electrode)}

A rod of spectrographic graphite $(5 \mathrm{~mm}$ in diameter and $15 \mathrm{~mm}$ long) was inserted in a polyethylene sleeve, and about $3 \mathrm{~mm}$ of the other end of the protruded rod served as a measuring surface. This end of the rod was washed with acetone, dried in air for 3 hours, and dipped rapidly into the previously prepared PVC-COOH- $\beta$-CD-DOP solution. The solvent was allowed to evaporate in air after each dipping, and the dipping process was repeated 6-8 times to produce a uniform membrane on the surface of the graphite rod. Drops of mercury were added in the polyethylene sleeve to ensure electrical contact with the connection cable. The coated graphite rod was conditioned by soaking in a $10^{-3} \mathrm{M} \mathrm{MZ}$ solution for 12 hours, and stored in the same solution when not in use.

Sensor 2 fabrication (SP-coated graphite electrode)

The procedure was followed as under Sensor 1 fabrication (MZ-coated graphite electrode) starting from "A rod of spectrographic graphite with the connection cable". The coated graphite rod was conditioned by soaking in a $10^{-2} \mathrm{M}$ SP solution for 24 hours, and stored in the same solution when not in use.

\section{Direct determination of $M Z$ and $S P$ in their pure powdered samples}

The prepared electrodes in conjunction with the double junction $\mathrm{Ag} / \mathrm{AgCl}$ reference electrode were immersed in aqueous solutions of $\mathrm{MZ}$ and $\mathrm{SP}$ in the range of $\left(1 \times 10^{-5}\right.$ to $1 \times 10^{-3} \mathrm{M}$ and $1 \times 10^{-5}$ to $\left.1 \times 10^{-2} \mathrm{M}\right)$, respectively. They were allowed to equilibrate while stirring and the emfs were recorded within $\pm 1 \mathrm{mV}$. The membrane sensors were stored in double distilled water between measurements. Calibration graphs were plotted relating the recorded potentials vs. -log drug concentration. These calibration graphs or the computed regression equations were used for subsequent measurements of unknown concentrations of MZ and SP.

Application of the proposed method for determination of MZ and SP in Spirazole ${ }^{\circledR}$ tablets

Ten tablets were accurately weighed and powdered. Amounts of the powdered tablets equivalent to $0.0171 \mathrm{~g}$ of $\mathrm{MZ}$ and $0.0843 \mathrm{~g}$ of SP were accurately transferred into two separate $100-\mathrm{mL}$ measuring flasks, and the volume was completed to the mark to prepare a $10^{-3} \mathrm{M}$ aqueous solution of $\mathrm{MZ}$ and SP, respectively. The emfs produced by immersing the prepared electrodes in conjunction with the double junction $\mathrm{Ag} / \mathrm{AgCl}$ reference electrode in the prepared solutions were recorded, and the concentrations of MZ and SP were 
then determined from the calibration curves of the corresponding drug or from the corresponding regression equation.

\section{Results and discussion}

The preparation and application of microelectrodes have attracted much interest in recent analytical chemistry studies [39]. This is part of a general trend in analytical chemistry towards miniaturization. The features of voltammetric microelectrodes have been investigated extensively during the last few years with the aim of improving the characteristics of electrochemical methods and performing studies under conditions not possible with conventional electrodes $[40,41]$. A variety of electrode materials of different shapes and sizes have been reported, but the most commonly used electrode materials are platinum [42], gold [43] and carbon fiber [44].

The replacement of the classical internal filling solution in potentiometric sensors is important because that design offers a number of advantages such as simplicity, lower cost, better mechanical flexibility and possibility of miniaturization. In ionselective electrode research there have been many attempts to replace the conventionally employed internal filling solutions for solid contacts [42].

\section{Sensors fabrication}

In the present work, the microsized graphite rods were coated with thin films of PVC-COOH- $\beta$-CD-DOP, and used as potentiometric sensors for MZ and SP. Upon soaking these sensors in $1 \times 10^{-3} \mathrm{M} \mathrm{MZ}$ and $1 \times 10^{-2} \mathrm{M}$ SP test solutions, a homogenous electroactive layer from PVC-COOH- $\beta$-cyclodextrin-DOP-drug was formed, which induces a potentiometric response for the two studied drugs.

$D O P$ (a non polar plasticizer) was found to be the optimum available mediator for the PVC-COOH membrane sensors. It plasticizes the membrane and adjusts the membrane permittivity to give the highest possible selectivity and sensitivity. Cyclodextrins are optically active oligosaccharides that form inclusion compounds in aqueous and solid states with organic molecules. They were previously applied as sensor ionophores to potentiometric ISEs for the determination of protonated amines [45] and chiral molecules incorporating aryl rings [46].

In most cases reported, the interaction is classical. However, there have been rare reports of cooperative interactions in the field of cyclodextrins, concerning either natural cyclodextrins or synthetic cyclodextrin derivatives [28]. In the case of natural cyclodextrins, cooperative binding with certain guest molecules has been mostly attributed to intermolecular hydrogen bonding between the CD molecules, while intermolecular interactions between both the host and guest molecules, hydrogen bonds, hydrophobic interactions and Van der Waals forces, contribute to cooperative binding processes when synthetic CDs are used [26]. $\beta$ $\mathrm{CD}$ based sensors showed accurate results in both response and selectivity.

Once $\mathrm{PVC}-\mathrm{COOH}$ has two recommended properties that are the partial dissociation and the high adhesion [47], sensors 1 and 2 were simply fabricated without the need of ion association complex. They were only preconditioned by 
soaking in the corresponding drug solution for 12 or 24 hours where acid base interactions take place between the dissociated $\mathrm{COO}^{-}$group of the $\mathrm{PVC}$ and the quaternary nitrogen atom of the drug in the test solution, until chemical equilibrium is attained.

PVC-COOH also acts as a regular support matrix as trap for the ion and as polymeric matrix to immobilize the sensor and to attain the formation of highly stable complex.

\section{Sensors calibration and response time}

Electrochemical performance characteristics of the proposed sensors were systematically evaluated according to IUPAC standards [48].

Table 1 shows the results obtained over a period of six months for two different assemblies of each sensor. Typical calibration plots are shown in Fig. 1. The sensors displayed constant potential readings within $\pm 2 \mathrm{mV}$ from day to day and the calibration slopes did not change by more than $\pm 2 \mathrm{mV}$ per decade over a period of 5 and 6 weeks for sensor 1 and sensor 2, respectively.

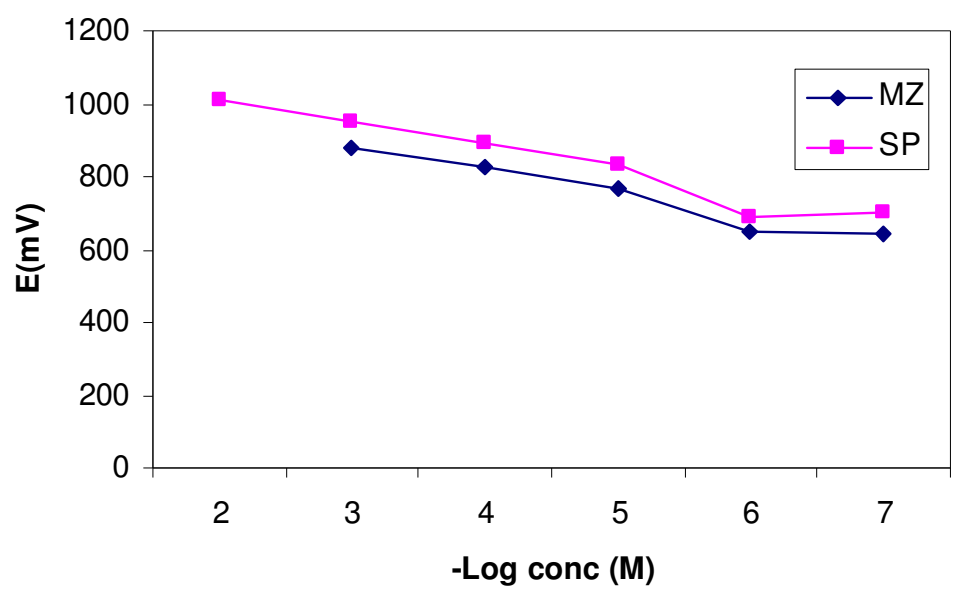

Figure 1. Profiles of the potential in $\mathrm{mV} /-\log$ concentrations (M) of $\mathrm{MZ}$ and $\mathrm{SP}$ of sensors 1 and 2 , respectively.

The required time for the sensors to reach values within $\pm 2 \mathrm{mV}$ of the final equilibrium potential after increasing drug concentration 10-folds, was found to be 45 and 30 seconds, for sensors 1 and 2, respectively. The slopes of the calibration plots were 58 and $59.3 \mathrm{mV} /$ concentration decade for sensor 1 and 2 , respectively, the typical value of monovalent substances, as these drugs behave as monovalent cations via their quaternary nitrogen atom.

\section{Effect of $p H$ and temperature}

In the measurements with the two investigated sensors, the different factors affecting the response of the electrodes (emfs) were studied to reach the optimum experimental conditions. A pH value within the range 5.5-7.5 was found to be optimum from the point of view of both sensor function and the chemical form of the test solution; both $\mathrm{MZ}$ and SP were in the cationic form in acidic media. Fig. 2 shows the potential $\mathrm{pH}$ profile for $10^{-3}$ and $10^{-4} \mathrm{M}$ drug solutions. Above $\mathrm{pH}$ 7.5 , the potentials displayed by the sensors decrease due to the formation of non- 
protonated drugs. Below $\mathrm{pH} 5.5$, the potentials displayed by the sensors were noisy and unbalanced. It is apparent that the sensors responses are fairly constant in solutions of $\mathrm{pH}$ 5.5-7.5.

Table 1. Response characteristics of the investigated selective electrodes and validation parameters of the response and of the regression equations.

\begin{tabular}{c|c|c}
\hline Parameters & $\begin{array}{c}\text { MZ-coated graphite } \\
\text { electrode }\end{array}$ & $\begin{array}{c}\text { SP-coated graphite } \\
\text { electrode }\end{array}$ \\
\hline \multicolumn{2}{c}{ Validation of the regression equations } \\
Slope (mV/ decade)* & 58 & 59.3 \\
Intercept (mV) & 1055 & 1127 \\
SE of the slope & 0.5774 & 0.9899 \\
SE of the intercept & 2.3570 & 3.6373 \\
Correlation coefficient & 0.9999 & 0.9996 \\
Concentration range (M) & $10^{-5}-10^{-3}$ & $10^{-5}-10^{-2}$ \\
LOD (M)** & $6.8 \times 10^{-7}$ & $5.9 \times 10^{-6}$ \\
Response time (Sec.) & 45 & 30 \\
Working pH range & $5.5-7.5$ & $5.5-7.5$ \\
Stability (weeks) & 5 & 6 \\
Accuracy (mean \pm S.D.) $*$ & $99.86 \pm 0.249$ & $99.69 \pm 0.856$ \\
R.S.D. & $0.250 \%$ & 0.860 \\
Repeatability \% *** & Precision & $99.10 \pm 0.276$ \\
Intermediate precision \% **** & $100.03 \pm 0.175$ & $99.07 \pm 0.179$ \\
\hline
\end{tabular}

- Average of five determinations. ** Limit of Detection (LOD) defined as drug concentration obtained at the intersection of the extrapolated high concentration (linear segment) with the low concentration (zero slope segment) of the calibration plot. *** The intraday $(\mathrm{n}=5)$ mean values \pm RSD of samples of concentrations $10^{-3}$ and $10^{-4} \mathrm{M}$ of each MZ and SP, respectively. **** The inter-day ( $\mathrm{n}=5$ ) mean values $\pm \mathrm{RSD}$ of samples of concentrations $10^{-3}$ and $10^{-4} \mathrm{M}$ of each MZ and SP.

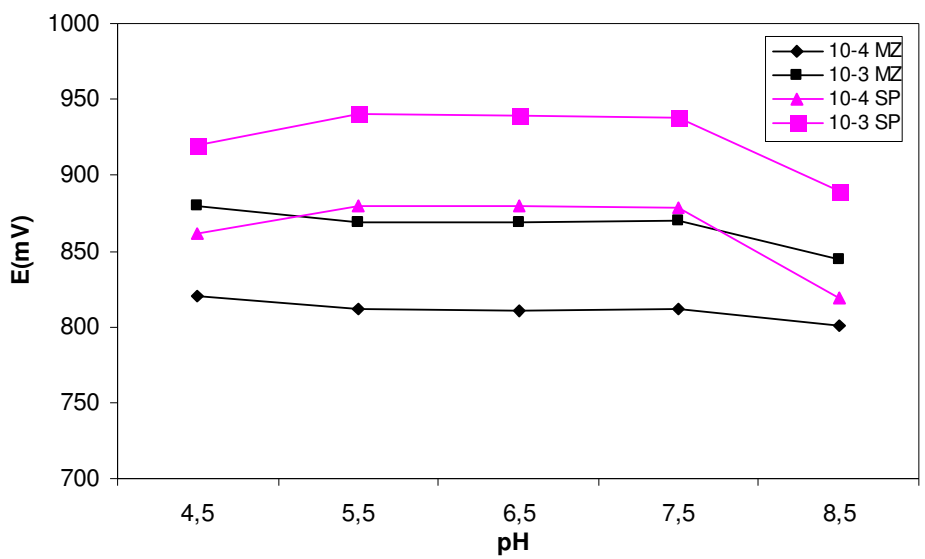

Figure 2. Effect of $\mathrm{pH}$ on the response of sensors 1 and 2. 


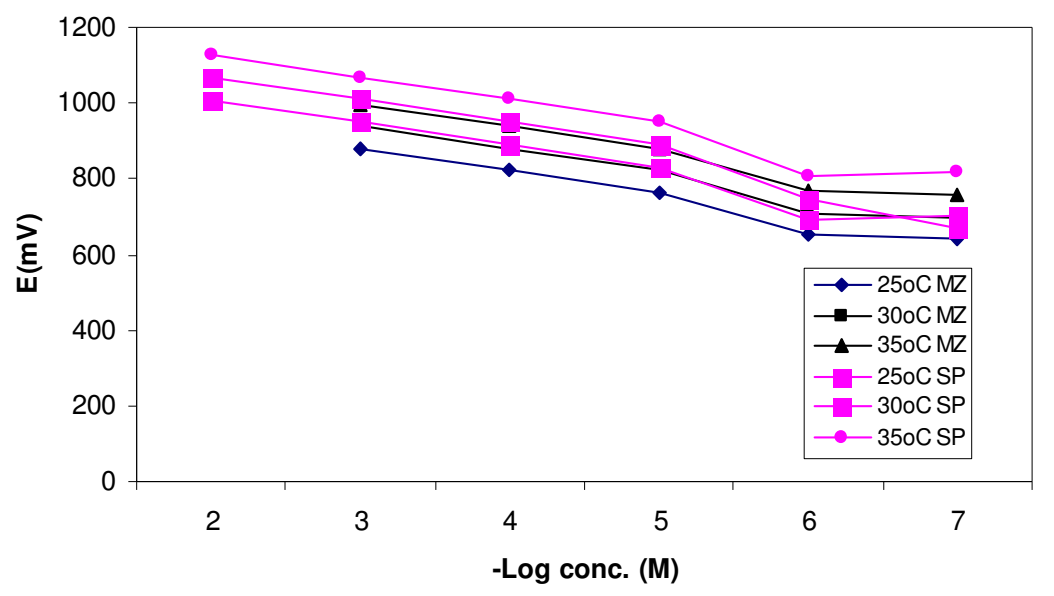

Figure 3. Effect of temperature on the response of sensors 1 and 2.

Upon studying the effect of temperature, the suggested sensors exhibit slight gradual increase in their potentials as the temperature increases in the range of $25-35{ }^{\circ} \mathrm{C}$; however, the calibration graphs obtained at different temperatures were parallel, and the slope and response time did not significantly vary with variation of temperature, indicating reasonable thermal stability of the suggested sensors up to $35^{\circ} \mathrm{C}$ (Fig. 3).

\section{Sensor selectivity}

The effect of interfering substances upon the performance of the sensors was studied by separate solutions method [48].

The performance of the two sensors in the presence of tablets excipients, organic and inorganic related substances and also some anti-infective drugs, was assessed by measuring and comparing the potentiometric selectivity coefficients. The results revealed that the proposed membrane sensors displayed high selectivity, and that no significant interference was observed from interfering species, Table 2 .

Table 3 shows the results obtained for the determination of MZ and SP in Spirazole ${ }^{\circledR}$ tablets, proving the applicability of the method without prior treatment or extraction, using sensor 1 for the determination of MZ and sensor 2 for the determination of SP, as demonstrated by the accurate and precise percentage recovery; the results obtained were also compared with those obtained by using reported method [27]. No significant difference in results was found.

Table 1 shows all the validation parameters of the proposed method including linearity, range, accuracy and precision. 
Table 2. Potentiometric selectivity coefficients $\left(\mathrm{K}^{\mathrm{pot}}{ }_{1 \text { ry }}\right.$ ion $)$ of the two proposed electrodes.

\begin{tabular}{ccc}
\hline \multirow{2}{*}{ Interferent** $^{*}$} & \multicolumn{2}{c}{ Selectivity coefficient* } \\
\cline { 2 - 3 } & Sensor 1 & Sensor 2 \\
\hline Spiramycin & $7.24 \times 10^{-6}$ \\
\hline Metronidazole & & $6.03 \times 10^{-5}$ \\
\hline Ampicillin & $7.94 \times 10^{-6}$ & $6.30 \times 10^{-5}$ \\
\hline Amikacin & $4.27 \times 10^{-5}$ & $8.71 \times 10^{-5}$ \\
\hline Cefoperazone & $3.39 \times 10^{-5}$ & $9.12 \times 10^{-6}$ \\
\hline Ornidazole & $1.70 \times 10^{-5}$ & $4.68 \times 10^{-5}$ \\
\hline Lactose & $4.16 \times 10^{-5}$ & $3.63 \times 10^{-5}$ \\
\hline MgSO 4 & $4.90 \times 10^{-5}$ & $2.88 \times 10^{-5}$ \\
\hline Talc & $1.82 \times 10^{-5}$ & $8.13 \times 10^{-5}$ \\
\hline Starch & $4.37 \times 10^{-5}$ & $6.76 \times 10^{-5}$ \\
\hline $\mathrm{NaCl}$ & $2.51 \times 10^{-5}$ & $5.89 \times 10^{-5}$ \\
\hline
\end{tabular}

* Average of 3 determinations. ** All interferents are in the form of $1 \times 10^{-3} \mathrm{M}$ solution.

Table 3. Statistical comparison for the results obtained by the proposed electrodes and a reported HPLC method [27] for the analysis of MZ and SP in Spirazole® tablets.

\begin{tabular}{ccccc}
\hline Item & MZ & $\begin{array}{c}\text { Reported HPLC } \\
\text { method }^{* *}\end{array}$ & SP & $\begin{array}{c}\text { Reported HPLC } \\
\text { method }^{* *}\end{array}$ \\
\hline Mean & 98.19 & 98.3 & 99.41 & 99.05 \\
SD & 1.132 & 1.481 & 0.860 & 1.082 \\
RSD\% & 1.269 & 1.500 & 0.865 & 1.090 \\
$\mathbf{n}$ & 5 & 5 & 5 & 5 \\
Variance & 1.281 & 2.193 & 0.740 & 1.171 \\
Student's t-test & $0.089(2.31)^{*}$ & & $0.393(2.31)^{*}$ & \\
F value & $1.712(6.3382)^{*}$ & & $1.582(6.3382)^{*}$ & \\
\hline
\end{tabular}

* The values in parentheses are the corresponding tabulated values at $\mathrm{p}=0.05$. ** HPLC method (using phosphate buffer $\mathrm{pH}$ 2.4: acetonitrile, 70:30 v/v, C-18 column, flow rate $1 \mathrm{~mL} \mathrm{~min}^{-1}$, at $232 \mathrm{~nm}$ ).

\section{References}

1. The Merck Index. An Encyclopedia of Chemicals, Drugs and Biological, $13^{\text {th }}$ Ed., Merck \& Co., Inc. (2002).

2. A.G. Gilman, L.E. Limbird, J.G. Hardman, Goodman \& Gilman's, The Pharmacological Basics of Therapeutics, $9^{\text {th }}$ ed., McGraw-Hill, New York. (1996).

3. K.C. Lamp, C.D. Freeman, N.E. Klutman, M.K. Lacy, Clin. Pharmacokinet. 36 (1999) 353. 
4. British pharmacopoeia through internet communications, http://www. pharmacopoeia.co.uk/ixbin/bp.cgi (2008).

5. P. Mourier, A. Brun, J. Chromatogr. B 704 (1997) 197. 10.1016/S03784347(97)00477-5

6. K. Ninomiya, Antibiotics for Animals, Youkendo Press, Tokyo (1987) 307.

7. F. Li, Y.Y. Ye, W.P. Jia, Chin. J. Pharm. Anal. 26 (2006) 1311.

8. H. Yao, X.Z. Zhang, X.Z. Li, Shaanxi Yaowu Fenxi Zazhi 20 (2000) 198.

9. X. Xia, X.W. Li, J.Z. Shen, S.X. Zhang, S.Y. Ding, H.Y. Jiang, J. AOAC Int. 89 (2006)1116.

10. C. Sagan, A. Salvador, D. Dubreuil, P.P. Poulet, D. Duffaut, I. Brumpt, J. Pharm. Biomed. Anal. 38 (2005) 98. 10.1016/j.jpba.2004.12.033

11. D.K. Bempong, R.G. Manning, T. Mirza, L. Bhattacharyya, J. Pharm. Biomed. Anal. 38 (2005) 776. 10.1016/j.jpba.2005.02.019

12. Q.Y. Jiang, J. Liu, H.Y. Gu, Yaowu Fenxi Zazhi 26 (2006) 777.

13. Z.F. Fu, H. Chen, Z.J. Zhang, Fenxi Shiyanshi 23 (2004) 1.

14. A.A. Salem, H.A. Mossa, B.N. Barsoum, J. Pharm. Biomed. Anal. 41 (2006) 654. 10.1016/j.jpba.2005.12.009

15. W.R. Jin, W. Li, Q. Xu, Q. Dong, Electrophoresis 21 (2000) 1409. 10.1002/(SICI)1522-2683(20000401)21:7

16. B. Rezaei, S. Damiri, Electrochim. Acta 55 (2010) 1801. 10.1016/j.electacta. 2009.10.070

17. X.M. Du, N.Y. Sun, L. Zhao, Yaowu Fenxi Zazhi 14 (1994) 56.

18. Y. Hua, F. Pan, Zhongguo Yiyao Gongye Zazhi 24 (1993) 179.

19. C. Sun, R. Yu, Q. Yang, S. Sheng, X. Zhao, Yaoxue Xuebao 22 (1987) 515.

20. M. Pendela, C. Govaerts, J. Diana, J. Hoogmartens, A. van Schepdael, E. Adams, Rapid Comm. Mass Spectrometry 21 (2007) 599. 10.1002/rcm.2868

21. W. Li, Y.M. Chu, H.M. Wen, G.Y. Liu, J. Zhang, Yaowu Fenxi Zazhi 26 (2006) 1465.

22. H.K. Chepkwony, A. Vermaelen, E. Roets, J. Hoogmartens, Chromatographia 54 (2001) 51. 10.1007/BF02491832

23. H.R. Gonzalez, Y.M. Li, A. Schepdael, E. Roets, J. Hoogmartens, Electrophoresis 20 (1999) 2407. 10.1002/(SICI)1522-2683(19990801) 20:12<2412::AID-ELPS2412>3.0.CO;2-F

24. Y.F. Yang, B. Wang, Electrophoresis 17 (1996) 359. 10.1002/elps.1150170215

25. C. Situ, C.T. Elliott, Anal. Chim. Acta 529 (2005) 89. 10.1016/j.aca.2004.08.013

26. H.M. Maher, R.M. Youssef, R.H. Khalil, S.M. El-Bahr, J. Chromatogr. B 876 (2008) 175. 10.1016/j.jchromb.2008.10.033

27. H.M. Maher, R.M. Youssef, Chromatographia 69 (2009) 345. 10.1365/s10337008-0865-2

28. E.E. Sideris, G.N. Valsami, M.A. Koupparis, P.E. Macheras, Eur. J. Pharm. Sci. 7 (1999) 271. 10.1016/S0928-0987(98)00035-9

29. M.S. Stanley, K.L. Busch, A. Vincze, J. Planar. Chromatogr. Mod. TLC 1 (1988) 76.

30. K. Prasad, R. Kala, T.P. Rao, G.R.K. Naidu, Anal. Chim. Acta 566 (2006) 69. 10.1016/j.aca.2006.02.064

31. M. Shamsipur, F. Mizani, M.F. Mousavi, N. Alizadeh, K. Alizadeh, H. Eshghid, H. Karami, Anal. Chim. Acta 589 (2007) 22. 10.1016/j.aca.2007.02.030

32. X. Ji, B. Jin, J. Ren, J. Jin, T. Nakamura, J. Electroanal. Chem. 579 (2005) 25. 10.1016/j.jelechem.2005.01.020 
33. W. Peng, E. Wang, Anal. Chim. Acta 281 (1993) 663. 10.1016/00032670(93)85028-I

34. H.J. James, G. Carmack, H. Freiser, Anal. Chem. 44 (1972) 856. 10.1021/ac60312a046

35. M. Bender, M. Komiyama, In Cyclodextrin Chemistry; Springer: Berlin, Hiedelberg, Germany, 1978.

36. B. Kieser, C. Fietzek, R. Schmidt, G. Belge, U. Weimar, V. Schurig, G. Gauglitz, Anal. Chem. 74 (2002) 3005. 10.1021/ac015689k

37. D. Diamond, "Principles of Chemical, Biological Sensors", in: Chemical Analysis; Wiley, 150, (1998).

38. B.A. Conway, "Ion Selective Electrodes"; Ottawa Press (1995).

39. T. Isoda, N. Takahara, H. Imanaga, R. Imamura, S. Hasegawa, K. Noguchi , T. Kimura, Sensors Actuators B: Chem. 120 (2006) 1. 10.1016/j.snb.2006.01.039

40. R.M. Wightman, Anal. Chem. 53 (1981) 1125A. 10.1021/ac00232a004

41. A.M. Bond, Analyst 119 (1994) 1R. 10.1039/AN994190001R

42. A.M. El-Kosasy, M.Y. Salem, G.M. El-Bardicy, M.K. El-Rahman, Chem. Pharm. Bull. 56 (2008) 753.

43. L. Wang, J. Wang, F. Zhou, Electroanalysis 16 (2004) 627. 10.1002/elan. 200302849

44. T.E. Edmonds, Anal. Chim Acta 175 (1985) 1. 10.1016/S0003-2670(00)82713-0

45. M.C.B.S.M. Montenegro, J.L.F.C. Lima, Microchim. M. Acta 131 (1999) 187. 10.1007/PL00010030

46. J.L.F.C. Lima, M.C.B.S.M. Montenegro, A.M.R da Silva, J. Pharm. Biomed. Anal. 8 (1990) 701. 10.1016/0731-7085(90)80106-Y

47. S.S. Hassan, M.M. Amer, S.A. Abd El-Fatah, A.M. El-Kosasy, Talanta 46 (1998) 1395. 10.1016/S0039-9140(98)00008-3

48. Y. Umezawa, P. Bühlmann, K. Umezawa, K. Tohda, S. Amemiya, Pure Appl. Chem. 72 (2000) 1851. 10.1351/pac200072101851 